\title{
CORRESPONDENGE
}

\section{THE WARLINGHAM PARK INQUIRY}

Dear Sir,

Dr Glaister's critique of the Warlingham Park Inquiry (Bulletin, August 1977, p 10) seems to me cock-eyed and misleadingly unbalanced. He evidently believes there is such a thing as a 'normal rate of suicide' (presumably established by divine intervention at Warlingham in $1960-65$ or earlier), and that that hospital suffered from an abnormally low rate of suicide in the eight years 1966-73. It is this abnormality, he says, which should have been studied by the Inquiry Committee, and not the rise above the 'normal' rate $(P=0.05)$ in the years 1974 and 1975 which preoccupied them.

He thinks the Report of the Inquiry entirely inadequate and a fiasco because it makes such a poor showing as a scientific contribution to the epidemiology of suicide, rather as a grocer might belittle it because there is no mention of the price of cheese. In fact, however, the Report is chiefly concerned with the running of psychiatric services, both in hospital and in the community, and its analyses and proposals are likely to be of great value to those concerned in providing such services-consultants, nursing officers, hospital administrators. It has some useful things to say about cultivating the friendship of your local newspaper. It draws attention to the rather careless collection and foolish definition of hospital suicide statistics by the DHSS. It points to the need for monitoring the working of community services as staff are moved into them and the need for good quick communication throughout a comprehensive service. It attempts an operational definition of suicidal risk which could be helpful to doctors and nurses required to assess it. Above all, it has a good deal to say on the changing work roles of the psychiatric nurse, and what this means in terms of essential minimum staffing of the different kinds of wards and out-patient services.

One of the grave failures of the NHS, because it is probably at the bottom of the various hospital scandals which have led to Inquiries, and of the persistent calls for more physical security, has been the assessment of nursing needs in terms of beds or of bodies (quite inappropriate for psychiatry) instead of in terms of work loads. No doubt we shall be hearing a lot more about this, from the unions if from no one else. Don't let Dr Glaister misdirect you about the significance of Warlingham.

The Maudsley Hospital,

John Grammer

London $\mathrm{SE}_{5} 8 \mathrm{AZ}$

\section{FORTHCOMING EVENTS}

\section{University of Birmingham}

An introductory course in Family Therapy, consisting of ten weekly half-day sessions from 5 October7 December, will be held at the Centre for Postgraduate Psychiatry, Uffculme Clinic, Queensbridge Road, Moseley, Birmingham $\mathrm{B}_{13} 8 Q \mathrm{D}$, and is intended for psychiatrists, social workers, psychologists, etc. who wish to gain basic knowledge of the theory and practice of family therapy. The fee is £35. Further details and application forms may be obtained from Christine Neal at the above address.

\section{British Association of Counselling}

There will be an inaugural meeting of the 'Counselling in a Medical Setting' Division on Saturday, 22 October, at the Community Health Foundation, 188
Old Street, London, E.C.I. Details from Dr A. J. Haines, 4 Greenland Road, London, N.W.I (01-485 0981 ).

\section{British Psycho-Analytical Society}

The British Psycho-Analytical Society announces two one-day courses at which talks and discussions will be presented by members of the Society. Both courses will be held at the Institute of PsychoAnalysis, London, and are open to medical and other professional workers. The fee for each day is $£_{10}$, which includes morning coffee and afternoon tea; admission by ticket only.

Saturday, 15 October, 9.30 am-12.30 pm and 2.005.00 pm: A one-day course on 'Basic PsychoAnalytical Concepts'. 